\title{
A System of Simultaneous Equations (SEM) for the Study of the Effectiveness of the Japanese Monetary Policy
}

\author{
Rosa Ferrentino ${ }^{1 *}$, Luca Vota ${ }^{2}$ \\ ${ }^{1}$ Department of Economic and Statistics Sciences, University of Salerno, Fisciano, Italy \\ ${ }^{2}$ Economics and Finance Scholar, University of Salerno, Fisciano, Italy \\ Email: ^rferrentino@unisa.it, votaluca@yahoo.it
}

How to cite this paper: Ferrentino, R. and Vota, L. (2021) A System of Simultaneous Equations (SEM) for the Study of the Effectiveness of the Japanese Monetary Policy. Applied Mathematics, 12, 407-420. https://doi.org/10.4236/am.2021.125029

Received: April 6, 2021

Accepted: May 23, 2021

Published: May 26, 2021

Copyright () 2021 by author(s) and Scientific Research Publishing Inc. This work is licensed under the Creative Commons Attribution-NonCommercial International License (CC BY-NC 4.0). http://creativecommons.org/licenses/by-nc/4.0/ (c) (i) (8) Open Access

\begin{abstract}
In this paper, the authors study the effectiveness of the Japanese monetary policy set by the Bank of Japan (BOJ) to contrast the three major crises that the country has experienced since the second half of the 90s: that of the lost decade, that of 2008 and that of the Covid-19 pandemic. To this end, they use a particular type of mathematical-statistical model that is widely applied today in the economic field, namely a simultaneous equation model (SEM). This simultaneous equation model is estimated through an Iteratively reweighted least squares (IRLS) using quarterly historical series in the sample period Q1 1994 - Q2 2020. All data are in real terms. The results, appropriately compared with those of other authors, suggest that the monetary policy has a (limited) impact only on the interbank market. The fiscal policy, instead, has a greater ability to influence the money supply, the private consumption and the inflation expectations.
\end{abstract}

\section{Keywords}

Simultaneous Equations Model, Mathematical Methods, Economic Policy, Iteratively, Reweighted Least Square, Abenomics

\section{Introduction}

The debate regarding the effectiveness of the Japanese monetary policy has developed since the end of the 1990s, together with that relating to the causes of the structural change that the national economy was experiencing in those years. In fact, precisely between the end of the 90s and the early 2000s, the very long period of GDP growth that began after World War II finished and started a new 
phase characterized by the alternation of recession and deflation with stagflation (crisis of the Lost Decade).

Just in this context of crisis, an interesting debate, which saw Bernanke, Blanchard, Krugman and Ueda as the main protagonists, caught on.

Bernanke [1] analyzed the main monetary policy variables between 1991 and 1994, namely in the period in which was forming the real estate and financial bubble whose explosion would have triggered the recession, and criticized the $\mathrm{BOJ}$ arguing that its policies at that time were not sufficiently expansive.

Blanchard [2] and Krugman [3] tried to identify the appropriate monetary policies to stimulate the expected inflation and the actual inflation near the Zero Lower Bound (ZLB). Their proposal consisted in giving up setting an inflation target and increasing the monetary base by $20 \%$.

A similar position to Bernanke's one was expressed at the same time by Ueda [4], who stated that in those years the BOJ should have engaged an asset purchasing operation on the financial market or, alternatively, accept new types of assets (such as commercial paper, corporate bonds and REPOs) as collateral for its financing operations.

The thesis of Bernanke, Ueda, Blanchard and Krugman according to which the responsibility for the bursting of the bubble in the early 1990s should be attributed to inappropriate choices by the BOJ has been contested by Leigh [5], according to whom, instead, the monetary policies of the early 1990s would have been neutralized by a series of adverse shocks that hit the Japanese economy in those years.

Starting from 2013, the attention of scholars has focused on the monetary policies implemented in the context of Abenomics that is the economic policy plan conceived by the government and aimed at helping the Japanese economy exit from the stagflation phase that began in 1991. Koeda [6], using the SVAR methodology, studied the effects of the Quantitative and Qualitative Easing (QQE) and discovered that since 2013 it has been useful in increasing the per capita GDP growth rate and inflation.

A more critical opinion was expressed by Fukuda [7], who stated that the QQE and the Negative Interest Rate Policy (NIRP) caused an outflow of capital from Japan to the other economies of the Asian continent due to the lowering of the profitability of domestic investments. According to the author, these outflows were mainly directed towards the stock market.

Also, other authors [8] studied the impact of Abenomics on the Japanese financial market and found that it has been of little use in improving the expectations of foreign investors and attracting foreign investments. For an overall evaluation of Abenomics, the contribution of De Michelis and Iacovello [9], who demonstrated, through a new-Keynesian DSGE model, that the policies of Abenomics have helped to contrast the deflationary tendency of the lost decade, is important.

Another important monetary policy tool deserves particular attention, namely the forward guidance which was first adopted by the BOJ in 1999 and, at least 
until today, has been conducted by making explicit the objectives of the monetary policy authorities through a specific communication strategy.

Many independent scholars, however, spoke out critically about forward guidance. Among these, Gertler [10] noted that forward guidance has not had any significant effect on inflation, although its increasingly penetrating use by the Bank of Japan (BOJ) since 2013.

Filardo and Hofmann [11] then estimated the realized volatility of the expected interest rates over a time horizon of one year, two years and five years. According to their results, the volatility, achieved in the periods in which forward guidance is active, tends to coincide with that of the periods in which forward guidance is not active, in each of the three-time horizons.

This interesting evidence further questions the usefulness of forward guidance.

In fact, the two authors note that, among all the economies considered, the Japanese one is the only one in which this happens and admit the objective difficulty in expressing an exhaustive evaluation of forward guidance.

\section{Research Aims}

The aim of this paper is to offer a generalized analysis of the effectiveness of the Japanese monetary policy, from the beginning of the crisis of the Lost Decade until today. For this purpose, the authors present a simultaneous equations model (SEM) that includes the dynamic money multiplier, the money supply function, a private consumption function, a private investment function, an expected inflation function and an interbank call money market rate function (that represents the effects of the fiscal and of the monetary policy operations on the credit market).

The choice of a simultaneous equation model is due to the fact that the structural equation models (Structural Equation Models or SEM) are one of the most used techniques for data analysis and have spread to all fields of social and behavioral sciences (and also in many other sectors), because they allow to explain complex phenomena using a limited number of indicators.

More precisely, the SEMs represent a multivariate statistical analysis technique that allows to examine the linear relationships between one or more independent variables and one or more dependent variables, which may be, in either case, measurable (namely directly observable) or latent (not directly observable and, therefore, indirectly measured through two or more detectable indicators or proxies).

This simultaneous equations model (SEM) is estimated through an iteratively reweighted least squares (IRLS), using quarterly historical series in the sample period Q1 1994 - Q2 2020 and at constant prices. Among the independent variables of the model, the government expenditure and the government debt were added, in order to control for the fiscal policy.

The main innovation of this manuscript consists in demonstrating that the 
monetary policy has no effect on the GDP, on the consumption, on the investments and on the inflation expectations, instead it has a limited impact on the interbank call money market rate.

Another important result is that the fiscal policy is able to influence the consumption, the money supply, the inflation expectations (even if slightly) and the interbank call money market rate.

In other words, the importance of this contribution lies in the fact that it addresses a controversial topic, widely discussed and which has aroused considerable interest in the academic community for a long time. The purpose of the authors, in fact, is to conduct a rigorous and impartial normative analysis of the Japanese economic policy, which stimulates the debate on the reasons of the decline of the Japanese economy.

The paper is organized as follows. In Section 1, an introduction relating to the subject of the manuscript is placed. In Section 2 the aims of the research are explained and the main results are summarized. In Section 3 the theoretical SEM model is presented and, after having appropriately described the data relating to each variable included in it, the coefficients of the system estimated through the IRLS are exposed. In Section 4 the results of the estimation of the previous paragraph are discussed, while in Section 5, finally, the conclusions are developed, remarking the innovative component of the article. The last part contains a detailed bibliography and an appendix divided into two sections.

\section{Model and Data}

As is well known, the constitutive unit of structural equation models is the structural equation, namely a regression equation that expresses the causal relationship existing between a dependent variable and several independent variables, while the causal links between the variables are formalized, as a whole, through a system of equations

The coefficients of such system may be calculated using the iteratively reweighted least squares (IRLS) estimator, a particular type of weighted least squares (WLS). Compared to the traditional Least squares, which provides the solutions of a function defined in the space $l^{2}$, the IRLS gives the solutions of a function defined in the space $l^{p}$ with $1 \leq p \leq 2$ and it is robust, as the weights are calculated as a function of leverage and residuals [12].

A brief description of the IRLS algorithm is presented by Li [13] (Cfr. Section I of the Appendix).

The dynamic system of simultaneous equations written by the authors is the following:

$$
\begin{gathered}
Y_{t}=\alpha_{1,1} M_{3_{t}}+\alpha_{1,2} Y_{t-1}+\alpha_{1,3} M_{3_{t-1}}+\alpha_{1,4} G_{t}+\alpha_{1,5} G_{t-1}+\alpha_{1,6} D_{t}+\varepsilon_{1 t} \\
M_{3_{t}}=\alpha_{2,1} Y_{t}+\alpha_{2,2} Y_{t-1}+\alpha_{2,3} M_{3_{t-1}}+\alpha_{2,4} G_{t}+\alpha_{2,5} G_{t-1}+\alpha_{2,6} D_{t}+\alpha_{2,7} D_{t-1}+\varepsilon_{2 t} \\
C_{t}=\alpha_{3,1} Y_{t}+\alpha_{3,2} Y_{t-1}+\alpha_{3,3} M_{1_{t}}+\alpha_{3,4} M_{1_{t-1}}+\alpha_{3,5} G_{t}+\alpha_{3,6} G_{t-1} \\
+\alpha_{3,7} D_{t}+\alpha_{3,8} D_{t-1}+\varepsilon_{3 t}
\end{gathered}
$$




$$
\begin{aligned}
I_{t}= & \alpha_{4,1} Y_{t}+\alpha_{4,2} M_{3_{t}}+\alpha_{4,3} i_{t}+\alpha_{4,4} i_{t-1}+\alpha_{4,5} r_{t}+\alpha_{4,6} r_{t-1}+\alpha_{4,7} n_{t}+\alpha_{4,8} n_{t-1} \\
& +\alpha_{4,9} s_{t}+\alpha_{4,10} s_{t-1}+\alpha_{4,11} G_{t}+\alpha_{4,12} G_{t-1}+\alpha_{4,13} D_{t}+\varepsilon_{4 t} \\
\pi_{t}^{e}= & \alpha_{5,1} \pi_{t}+\alpha_{5,2}\left(\pi_{t}-\pi_{t-1}^{e}\right)+\alpha_{5,3} M_{1_{t}}+\alpha_{5,4} M_{3_{t}}+\alpha_{5,5} i_{t}+\alpha_{5,6} r_{t}+\alpha_{5,7} s_{t} \\
& +\alpha_{5,8} n_{t}+\alpha_{5,9} G_{t}+\alpha_{5,10} G_{t-1}+\alpha_{5,11} D_{t}+\alpha_{5,12} D_{t-1}+\varepsilon_{5 t} \\
s_{t} & =\alpha_{6,1} I_{t}+\alpha_{6,2} M_{3_{t}}+\alpha_{6,3} i_{t}+\alpha_{6,4} r_{t}+\alpha_{6,5} n_{t}+\alpha_{6,6} G_{t}+\alpha_{6,7} G_{t-1} \\
& +\alpha_{6,8} D_{t}+\alpha_{6,9} D_{t-1}+\varepsilon_{6 t}
\end{aligned}
$$

where $Y_{t}$ is the national income; $M_{3_{t}}$ is the monetary aggregate $M_{3} ; G_{t}$ is the government expenditure; $D_{t}$ is the government debt; $M_{1_{t}}$ is the monetary aggregate $M_{1} ; i_{t}$ is the Basic discount and loan rate of the BOJ; $r_{t}$ is the rate of return of 10-year Japanese government bonds; $s_{t}$ is the Japanese interbank call money market rate; $n_{t}$ is the immediate rate of the BOJ (namely the interest rate applied on loans with a maturity of less than twenty-four hours); $I_{t}$ are the investments; $C_{t}$ is the private consumption; $\pi_{t}^{e}$ is the expected inflation at time $t$ for the period $t+1 ; \pi_{t}$ is the actual inflation; $\pi_{t-1}^{e}$ is the inflation expectation at time $t-1$ for the period $t$.

The (1) and (2) are, respectively, the dynamic money multiplier and the money supply function; (3) is a private consumption function; (4) is a private investment function; (5) represents the expected inflation; (6) is an interbank call money market rate function and it represents the consequences on the interbank credit market of the economic policy operations (among others).

In (5) the coefficients $\alpha_{5,1}$ and $\alpha_{5,2}$ represent, respectively, the adaptive component of the effective inflation and the forecast error committed by the operators at the current time (in other words, $\alpha_{5,2}$ is an expression of the rational component of the actual inflation at the current time).

The two variables government expenditure and government debt have been inserted into each of the six equations in order to control for the fiscal policy. Note in particular that these variables in (3) and (4) capture the crowding out effect on the private demand, an effect discussed in the Japanese case by recent contributions in the literature [14].

According to previous studies [15], the crowding out, during the 90s, did not have any effect on the interest rates in Japan; instead it implied a loss in the physical capital. This thesis is tested by Equation (6) of the model proposed here in relation to the sample period considered.

The proposed model was estimated using quarterly historical data collected in the sample period Q1 1994 - Q2 2020. These data are at constant prices.

The effective inflation is calculated with respect to the Consumer Price Index (CPI) with base year $2015(2015=100)$, instead break even inflation, namely the difference between the nominal rate of return and the real rate of return of the 10-year government bond, is used as a proxy for the expected inflation.

In the Japanese case, Kamada and Nakajima [16] construct a particular measure of the expected inflation based on Purchasing power parity (PPP) and find that, in the long run, it coincides with the break even inflation. This is precisely 
the reason why this particular measure is chosen here.

The government final consumption expenditure is considered for the government expenditure.

Regarding the Basic discount and loan rate, its value in each quarter is calculated as the average of the four corresponding monthly rates.

The model was identified using the method of instrumental variables. More precisely, the following thirteen exogenous variables were used as instruments:

$$
I_{t-1}, Y_{t-1}, M_{3_{t-1}}, G_{t}, G_{t-1}, D_{t}, D_{t-1}, M_{1_{t-1}}, i_{t-1}, r_{t}, r_{t-1}, n_{t-1}, s_{t-1} .
$$

It is easy to see that for the $i$-th equation of the system is verified:

$$
K-k \geq v-1
$$

where $K$ is the total number of exogenous variables, $k$ is the number of exogenous variables in the $i$-th equation and $v$ is the number of endogenous variables present in the $i$-th equation.

In other words, each equation of the system is correctly identified.

After presenting the SEM model and after explaining how its variables were measured and how it was identified, the estimation of the coefficients through the IRLS was carried out.

The output is shown below in Table 1 .

\begin{tabular}{|c|c|c|c|c|}
\hline \multicolumn{5}{|c|}{ Equation (1) } \\
\hline \multicolumn{5}{|c|}{ Dependent variable: $Y_{t}$} \\
\hline Coefficient $\hat{\alpha}_{i, j}$ & Estimated value & Standard error & $t$ ratio & p-value \\
\hline$\hat{\alpha}_{1,1}$ & -0.000176402 & 0.000336741 & -0.5239 & 0.6016 \\
\hline$\hat{\alpha}_{1,2}$ & 0.888290 & 0.0409553 & 21.69 & $5.51 \mathrm{e}-039^{\star * *}$ \\
\hline$\hat{\alpha}_{1,3}$ & 0.000186208 & 0.000348802 & 0.5338 & 0.5947 \\
\hline$\hat{\alpha}_{1,4}$ & 0.000907855 & 0.000628893 & 1.444 & 0.1521 \\
\hline$\hat{\alpha}_{1,5}$ & -0.000260441 & 0.00573977 & -0.9870 & 0.3261 \\
\hline$\hat{\alpha}_{1,6}$ & 0.00369258 & 0.00541278 & 0.6822 & 0.4967 \\
\hline \multicolumn{5}{|c|}{ Equation (2) } \\
\hline \multicolumn{5}{|c|}{ Dependent variable: $M_{3_{t}}$} \\
\hline Coefficient & Estimated value & Standard error & $t$ ratio & p-value \\
\hline$\hat{\alpha}_{2,1}$ & -14.9188 & 28.4791 & -0.5239 & -0.5239 \\
\hline$\hat{\alpha}_{2,2}$ & -37.7497 & 27.7456 & -1.361 & 0.1768 \\
\hline$\hat{\alpha}_{2,3}$ & 1.03527 & 0.00345112 & 300.0 & $9.23 e-146^{\star * *}$ \\
\hline$\hat{\alpha}_{2,4}$ & 0.0535138 & 0.184640 & 0.2898 & 0.7726 \\
\hline$\hat{\alpha}_{2,5}$ & -0.00710380 & 0.195867 & -0.03627 & 0.9711 \\
\hline$\hat{\alpha}_{2,6}$ & -4.47423 & 1.61860 & -2.764 & $0.0068^{\star * *}$ \\
\hline$\hat{\alpha}_{2,7}$ & 3.03196 & 1.54936 & 1.957 & $0.0532^{\star}$ \\
\hline
\end{tabular}

Table 1. Estimation of the coefficients of the SEM. 


\section{Continued}

Equation (3)

Dependent variable: $C_{t}$

\begin{tabular}{ccccc}
\hline Coefficient & Estimated value & Standard error & $\boldsymbol{t}$ ratio & p-value \\
\hline$\hat{\alpha}_{3,1}$ & 0.361828 & 0.0433683 & 8.343 & $5.31 \mathrm{e}-013^{* * *}$ \\
$\hat{\alpha}_{3,2}$ & 0.00122914 & 0.0414521 & 0.02965 & 0.9764 \\
$\hat{\alpha}_{3,3}$ & $-3.51175 \mathrm{e}-05$ & $3.59577 \mathrm{e}-05$ & -0.9766 & 0.3312 \\
$\hat{\alpha}_{3,4}$ & $-9.56796 \mathrm{e}-06$ & $3.81180 \mathrm{e}-05$ & -0.2510 & 0.8023 \\
$\hat{\alpha}_{3,5}$ & 0.00129260 & 0.000284876 & 4.537 & $1.65 \mathrm{e}-05^{* * *}$ \\
$\hat{\alpha}_{3,6}$ & $3.57584 \mathrm{e}-05$ & 0.000296702 & 0.1205 & 0.9043 \\
$\hat{\alpha}_{3,7}$ & -0.000849945 & 0.00248062 & -0.3426 & 0.7326 \\
$\hat{\alpha}_{3,8}$ & 0.000581131 & 0.00240057 & 0.2421 & 0.8092
\end{tabular}

Equation (4)

Dependent variable: $I_{t}$

\begin{tabular}{|c|c|c|c|c|}
\hline Coefficient & Estimated value & Standard error & $t$ ratio & p-value \\
\hline$\hat{\alpha}_{4,1}$ & 0.000131031 & $2.09448 \mathrm{e}-05$ & 6.256 & $1.39 \mathrm{e}-08^{\star * *}$ \\
\hline$\hat{\alpha}_{4,2}$ & $1.27448 \mathrm{e}-07$ & $7.76841 \mathrm{e}-08$ & 1.641 & 0.1045 \\
\hline$\hat{\alpha}_{4,3}$ & -0.828132 & 3.03306 & -0.2730 & 0.7855 \\
\hline$\hat{\alpha}_{4,4}$ & 0.976300 & 1.83140 & 0.5331 & 0.5953 \\
\hline$\hat{\alpha}_{4,5}$ & 0.739343 & 0.458909 & 1.611 & 0.1107 \\
\hline$\hat{\alpha}_{4,6}$ & 0.290224 & 0.484659 & 0.5988 & 0.5508 \\
\hline$\hat{\alpha}_{4,7}$ & 0.463779 & 1.64462 & 0.2820 & 0.7786 \\
\hline$\hat{\alpha}_{4,8}$ & 0.946332 & 1.48973 & 0.6352 & 0.5269 \\
\hline$\hat{\alpha}_{4,9}$ & -1.06582 & 2.29461 & -0.4645 & 0.6434 \\
\hline$\hat{\alpha}_{4,10}$ & -2.63836 & 2.42498 & -1.088 & 0.2796 \\
\hline$\hat{\alpha}_{4,11}$ & $2.60060 \mathrm{e}-07$ & -2.029 & -2.029 & $0.0454^{* *}$ \\
\hline$\hat{\alpha}_{4,12}$ & $-1.42536 \mathrm{e}-07$ & $1.38500 \mathrm{e}-07$ & -1.029 & 0.3062 \\
\hline$\hat{\alpha}_{4,13}$ & $-2.12833 e-06$ & $1.15831 \mathrm{e}-06$ & -1.837 & $0.0695^{\star}$ \\
\hline
\end{tabular}

Equation (5)

Dependent variable: $\pi_{t}^{e}$

\begin{tabular}{ccccc}
\hline Coefficient & Estimated value & Standard error & $\boldsymbol{t}$ ratio & p-value \\
\hline$\hat{\alpha}_{5,1}$ & -0.00460043 & 0.00136967 & -3.359 & $0.0012^{\star * *}$ \\
$\hat{\alpha}_{5,2}$ & -0.00274595 & 0.00156117 & -1.759 & $0.0822^{\star}$ \\
$\hat{\alpha}_{5,3}$ & $3.81756 \mathrm{e}-010$ & $1.27175 \mathrm{e}-010$ & 3.002 & $0.0035^{\star * *}$ \\
$\hat{\alpha}_{5,4}$ & $1.79915 \mathrm{e}-09$ & $5.30903 \mathrm{e}-010$ & 3.389 & $0.0011^{* * *}$ \\
$\hat{\alpha}_{5,5}$ & 0.0104874 & 0.0212498 & 0.4935 & 0.6229 \\
$\hat{\alpha}_{5,6}$ & 0.0272104 & 0.00329157 & 8.267 & $1.53 \mathrm{e}-012^{\star * *}$ \\
$\hat{\alpha}_{5,7}$ & -0.00509965 & 0.0110350 & -0.4621 & 0.6452 \\
\hline
\end{tabular}


Continued

\begin{tabular}{|c|c|c|c|c|}
\hline$\hat{\alpha}_{5,8}$ & -0.0130272 & 0.0159375 & -0.8174 & 0.4160 \\
\hline$\hat{\alpha}_{5,9}$ & $3.93663 \mathrm{e}-09$ & $1.10592 \mathrm{e}-09$ & 3.560 & $0.0006^{* * *}$ \\
\hline$\hat{\alpha}_{5,10}$ & $-2.96210 \mathrm{e}-010$ & $1.09311 \mathrm{e}-09$ & -0.2710 & 0.7871 \\
\hline$\hat{\alpha}_{5,11}$ & $-5.55518 \mathrm{e}-09$ & $8.55063 \mathrm{e}-09$ & -0.6497 & 0.5176 \\
\hline$\hat{\alpha}_{5,12}$ & $4.76485 \mathrm{e}-010$ & $8.57995 \mathrm{e}-09$ & 0.05553 & 0.9558 \\
\hline \multicolumn{5}{|c|}{ Equation (6) } \\
\hline \multicolumn{5}{|c|}{ Dependent variable: $S_{t}$} \\
\hline Coefficient & Estimated value & Standard error & $t$ ratio & p-value \\
\hline$\hat{\alpha}_{6,1}$ & -0.0103494 & 0.0190660 & -0.5428 & 0.5886 \\
\hline$\hat{\alpha}_{6,2}$ & $-1.71902 \mathrm{e}-08$ & $8.35808 \mathrm{e}-09$ & -2.057 & $0.0426^{\star *}$ \\
\hline$\hat{\alpha}_{6,3}$ & 0.0779864 & 0.365576 & 0.2133 & 0.8316 \\
\hline$\hat{\alpha}_{6,4}$ & 0.0683877 & 0.0550072 & 1.243 & 0.2170 \\
\hline$\hat{\alpha}_{6,5}$ & 0.791342 & 0.228179 & 3.468 & $0.0008^{* * *}$ \\
\hline$\hat{\alpha}_{6,6}$ & $-2.78812 \mathrm{e}-08$ & $1.52732 \mathrm{e}-08$ & -1.825 & $0.0712^{*}$ \\
\hline$\hat{\alpha}_{6,7}$ & $2.03636 \mathrm{e}-08$ & $1.55920 \mathrm{e}-08$ & 1.306 & 0.1949 \\
\hline$\hat{\alpha}_{6,8}$ & $-1.09966 \mathrm{e}-07$ & $1.43712 \mathrm{e}-07$ & -0.7652 & 0.4462 \\
\hline$\hat{\alpha}_{6,9}$ & $6.45760 \mathrm{e}-08$ & $1.35133 \mathrm{e}-07$ & 0.4779 & 0.6339 \\
\hline
\end{tabular}

According to the results of the Breusch-Pagan test for the residual diagonal variance-covariance matrix, the estimated IRSL model errors are independent (see Section II of the Appendix).

\section{Discussion of the Estimated Results}

In (1), the estimated coefficients $\hat{\alpha}_{1,1}$ and $\hat{\alpha}_{1,3}$ are statistically insignificant and this implies that in the period considered the dynamic money multiplier is zero, namely the real GDP is insensitive to changes in the monetary aggregate $M_{3}$. It is interesting to note that in the same equation $\hat{\alpha}_{1,4}$ and $\hat{\alpha}_{1,5}$ are also null, so the dynamic fiscal multiplier in the same period is also zero.

In (2), $\hat{\alpha}_{2,1}$ and $\hat{\alpha}_{2,2}$ are statistically not significant, demonstrating the fact that an increase in the real GDP does not involve an increase in the money supply. The interpretation of this result is that the monetary expansion programs undertaken by the BOJ, such as the Quantitative easing of 2001 and the Quantitative and qualitative easing of 2013, were, on the whole, useless. According to some economists, the lack of transmission of the monetary impulses to the economy is mainly attributable to the presence of "zombie banks", namely those banks that record a large amount of Non-performing loans (NPLs) in their balance sheets. However, this explanation cannot be considered exhaustive. Indeed, as observed by Gandrud and Hallerberg [17], many efforts have been made by Japanese authorities since the second half of the 1990s to address this problem and to recapitalize distressed banks. As a result, the Japanese non-performing loan ratio fell 
from $8 \%$ in 2002 to $1.1 \%$ in 2020 .

Instead, there is strong evidence $\left(\hat{\alpha}_{2,6}>0\right)$ that an increase in the government debt at the current time of $1 \%$ causes the money supply to contract strongly $(-4.47 \%)$. This outcome is not surprising. In fact, Japanese households have a high marginal propensity to save (that according to the authors is equal to $1-\hat{\alpha}_{3,1}=0.67$ ) and a marked preference for the government bonds over other assets. Therefore, the issue of new government bonds induces savers to purchase them by reducing the other assets belonging to $M_{3}$ that they hold in their portfolio (including, of course, the currency in circulation).

The coefficient $\hat{\alpha}_{2,7}$ is less significant and so it may be neglected.

In (3), the real GDP has a considerable effect on the private consumption $\left(\hat{\alpha}_{3,1}>0\right)$. The coefficient $\hat{\alpha}_{3,5}$ is very significant, but its dimension is very small and therefore may be ignored. The primary liquidity $\left(M_{1_{t}}\right.$ e $\left.M_{1_{t-1}}\right)$, on the other hand, does not influence private consumption at all $\left(\hat{\alpha}_{3,3}=\hat{\alpha}_{3,4}=0\right.$ ).

In (4), the values of the estimated coefficients suggest that private investments are rigid with respect to all dependent variables. In fact, although they are respectively significant at $1 \%$, at $5 \%$ and at $10 \%, \hat{\alpha}_{4,1}, \hat{\alpha}_{4,11}$ and $\hat{\alpha}_{4,13}$ are close to zero. The relevant result is that a change in the interest rates has no impact on the investments. The thesis supported by Barseghyan, which has been previously mentioned, is not verified.

In (5), the coefficient $\hat{\alpha}_{5,1}$ is very significant, negative and close to zero; instead the coefficient $\hat{\alpha}_{5,2}$ is small and not very significant. All other coefficients are either not significant or very close to zero and, therefore, negligible. This proves that Japanese operators formulate mainly adaptive expectations, that the forecast error they make is limited, that they expect a mild deflation and that interest rates (including those set by the BOJ) and the open markets operations are irrelevant. This evidence is consistent with the fact that, since the beginning of the crisis of the Lost Decade, phases of low inflation and negative inflation alternate in Japan.

The coefficient $\hat{\alpha}_{5,6}$ (positive and significant at $1 \%$ level) reveals that an increase in the 10 -years government bonds real interest rate has a small positive effect on the expected inflation. In some previous contributions, a relationship consistent with the one just described has been found: a decrease in the corporate tax rate and in the deficit-financed consumption tax corresponds to an increase in the real GDP growth rate and in an improvement in the inflation expectations [18].

In (6), the value and the high significance of the coefficient $\hat{\alpha}_{6,5}$ indicate that an increase in the immediate rate by the BOJ cause a growth in the interbank call money market rate. This evidence shows that the BOJ is able to influence the banking sector through its interest rate decisions. The remaining coefficients may be ignored because, again, they are either insignificant or close to zero.

\section{Conclusions}

From the results obtained, the authors deduce that monetary policy seems to 
have had particularly limited effectiveness in favoring Japan's exit from the long phase of lack of growth and deflation that began in the second half of the 1990s, but also in contrasting the financial crisis of 2008 and the 2020 recession caused by the Covid-19 pandemic.

In fact, from the estimates made, it is clear that the operations of the Bank of Japan significantly influence only the banking sector, while they seem to have a negligible impact on GDP, on consumptions, on investments and on expected inflation.

The government's fiscal policy, on the other hand, proves to be more effective. In fact, the increases in government expenditure imply a rise in private consumption, a change in the 10-years government bonds real interest rate influences the inflation expectations and the money supply may be regulated by issuing government bonds.

In any case, the fiscal multiplier and the investment multiplier are zero.

It is also important to note that the failure to improve inflation expectations may not be attributed to the limited rationality of the operators, who, as already pointed out, make a very limited error in formulating their forecasts. The responsibility, therefore, must rather be attributed to the inadequate economic policy decisions of policy makers (in particular monetary policy decisions).

The achievements reached by the authors in this paper are consistent both with those of the scholars who have criticized Japanese monetary policy since the early 1990s (already exposed in the first paragraph) and with the empirical evidences relating to the QE of 2001 and to the Abenomics of 2013, evidences which show that these policy interventions have been modest in macroeconomic terms.

In conclusion, it is possible to assert that only the expenditure and the taxation decisions by the government have some relevance (in any case limited) for the Japanese economy. As already mentioned above, the main innovation of this manuscript consists precisely in demonstrating that monetary policy has no effect on the GDP, on the consumption, on the investments and on the inflation expectations, while it has a small impact on the interbank call money market rate.

In light of these results, the expansionary fiscal policy, not the expansionary monetary policy, is probably expected to be the switch that will favor the Japanese recovery after the crisis caused by the Covid-19 pandemic.

\section{Conflicts of Interest}

The authors declare no conflicts of interest regarding the publication of this paper.

\section{Ethical Approval}

This article does not contain any studies with human participants performed by any of the authors. 


\section{References}

[1] Bernanke, B. (1999) Japanese Monetary Policy: A Case of Self-Induced Paralysis? Paper Presented at the ASSA meetings at Princeton University, Boston, MA.

[2] Blanchard, O. (2000) Bubbles Liquidity Traps and Monetary Policy. Paper Presented at a Conference of Institute for International Economics, Washington DC.

[3] Krugman, P. (1998) It's Baaack: Japan's Slump and the Return of the Liquidity Trap. Brookings Papers on Economic Activity, 1998, 137-205. https://doi.org/10.2307/2534694

[4] Ueda, K. (1999) Remarks Given by Kazuo Ueda, Member of the Policy Board of the Bank of Japan, at the Fed Conference on "Monetary Policy in a Low-Inflation Environment” in Woodstock, Vermont on October 20, 1999. https://www.boj.or.jp/en/announcements/press/koen_1999/ko9910b.htm/

[5] Leigh, D. (2009) Monetary Policy and the Lost Decade: Lessons from Japan. IMF Working Paper, 2009, 33 p. https://doi.org/10.5089/9781451873795.001

[6] Koeda, J. (2019) Macroeconomic Effects of Quantitative and Qualitative Monetary Easing Measures. Journal of the Japanese and International Economies, 52, 121-141. https://doi.org/10.1016/j.jjie.2018.12.006

[7] Fukuda, S. (2018) Impacts of Japan's Negative Interest Rate Policy on Asian Financial Markets. Pacific Economic Review, 23, 67-79. https://doi.org/10.1111/1468-0106.12253

[8] Kondo, Y., Nakazono Y., Ota, R. and Sui, Q.-Y. (2020) Heterogeneous Impacts of Abenomics on the Stock Market: A Fund Flow Analysis. Journal of the Japanese and International Economies, 55, 1-10. https://doi.org/10.1016/j.jjie.2019.101053

[9] De Michelis, A. and Iacovello, M. (2016) Raising an Inflation Target: The Japanese Experience with Abenomics. European Economic Review, 88, 67-87. https://doi.org/10.1016/j.euroecorev.2016.02.021

[10] Gertler, M. (2017) Rethinking the Power of Forward Guidance: Lessons from Japan. Monetary and Economic Studies, Institute for Monetary and Economic Studies, Bank of Japan, 35, 39-58. https://doi.org/10.3386/w23707

[11] Filardo, A. and Hoffman, B. (2014) Forward Guidance at the Zero Lower Bound. BIS Quarterly Review, March Volume, 37-53.

[12] Chatterjee, S. and Mächler, M. (1997) Robust Regression: A Weighted Least Squares Approach. Communications in Statistics. Communications in Statistics-Theory and Methods, 26, 1381-1394. https://doi.org/10.1080/03610929708831988

[13] Li, J. (2006) Conjugate Guided Gradient (CGG) Method for Robust Inversion and Its Application to Velocity-Stack Inversion. Geophysics, 71, 1-24.

https://doi.org/10.1190/1.2209547

[14] Funashima, Y. and Ohtsuka, Y. (2019) Spatial Crowding-Out and Crowding-in Effects of Government Spending on the Private Sector in Japan. Regional Science and Urban Economics, 75, 35-48. https://doi.org/10.1016/j.regsciurbeco.2019.01.008

[15] Barseghyan, L. (2006) Crowding Out and the Rate of Return on Capital in Japan. Japan and the World Economy, 18, 278-297.

https://doi.org/10.1016/j.japwor.2004.12.002

[16] Kamada, K. and Nakajima, J. (2014) On the Reliability of Japanese Inflation Expectations Using Purchasing Power Parity. Economic Analysis and Policy, 44, 259-265. https://doi.org/10.1016/j.eap.2014.08.004

[17] Gandrud, C. and Hallerberg, M. (2017) How Not to Create Zombie Banks: Lessons 
for Italy from Japan. Bruegel Policy Contribution No. 6, Bruegel.

[18] Ferrentino, R. and Vota, L. (2019) A Structural Vector Autoregression Model for the Study of the Japanese Inflation and of the Japanese Inflation. Advances in Management and Applied Economics, 9, 69-93. 


\section{Appendix}

\section{Section I}

The IRLS algorithm is summarized below.

Let consider the weighted vector of the residuals $\varepsilon$ :

$$
\varepsilon=W_{\varepsilon}\left(A W_{x} x-y\right)
$$

where $W_{\varepsilon}$ is the diagonal matrix of the weighted residuals and $W_{x}$ is the diagonal matrix of the weights of the independent variables.

The gradient of the WLS might be expressed through the (7) as:

$$
W_{x}^{\mathrm{T}} A^{\mathrm{T}} W_{\varepsilon}^{\mathrm{T}} \varepsilon=\frac{\partial}{\partial x^{\mathrm{T}}}\left(A W_{x} x-y\right)^{\mathrm{T}} W_{\varepsilon}^{\mathrm{T}} W_{\varepsilon}\left(A W_{x} x-y\right)
$$

The main diagonal elements of $W_{\varepsilon}$ are computed as:

$$
\operatorname{diag}\left(W_{\varepsilon}\right)_{i}=\left|\varepsilon_{i}\right|^{\frac{p-2}{2}}
$$

from which it is deduced that the weighted residuals norm in the space $l^{2}$ is equal to:

$$
\left\|W_{\varepsilon} \varepsilon\right\|_{2}^{2}=\varepsilon^{\mathrm{T}} W_{\varepsilon}^{2} \varepsilon
$$

The weighted elements of the main variable of the matrix $W_{x}$ are instead calculated as:

$$
\operatorname{diag}\left(W_{x}\right)_{i}=\left|x_{i}\right|^{\frac{2-p}{2}}
$$

from which it follows that the norm of the independent variable vector is given by:

$$
\left\|W_{x} x\right\|_{2}^{2}=x^{\mathrm{T}} W_{x}^{-2} x
$$

\section{Section II}

The Breusch-Pagan test for the diagonal matrix verifies the null hypothesis:

$$
H_{0}: \sigma_{i . j}=0
$$

against the alternative hypothesis:

$$
H_{1}: \sigma_{i . j} \neq 0
$$

where $\sigma_{i, j}$ is the generic element $i, j$ that is placed above the main diagonal of the variance-covariance matrix of the residuals.

The test statistic $L$ is equal to:

$$
L=T \sum_{m=1}^{M} \sum_{n=1}^{m-1} \sigma_{m n}^{2} \sim \chi_{(M(M-1) / 2)}^{2}
$$

where $T$ is the number of the observations and $M$ is the number of the equations of the system.

In this case, the log-determinant of the matrix is equal to 44.57 , while:

$$
\chi_{(15)}^{2}=21.01
$$


to which corresponds a p-value equal to 0.133 .

The null hypothesis is not rejected with a significance level $\alpha=0.01$. From this result is desumed that the errors are independent. 